\title{
The Impact of Electronic Clearing on Currency in Circulation in Mozambique
}

\author{
Samuel Garicai Arone \\ Department of Sciences and Technology, Open University, Lisbon, Portugal
}

Email address:

1500887@estudante.uab.pt

To cite this article:

Samuel Garicai Arone. The Impact of Electronic Clearing on Currency in Circulation in Mozambique. American Journal of Theoretical and Applied Statistics. Vol. 9, No. 5, 2020, pp. 210-218. doi: 10.11648/j.ajtas.20200905.14

Received: August 21, 2020; Accepted: September 8, 2020; Published: September 21, 2020

\begin{abstract}
Similar to the experience of other countries, payment habits in Mozambique have been changing. Indeed, innovations in transaction technology such as electronic payments have revolutionized the payment landscape in the economies. Although, in general, cash has remained the dominant payment instrument, it is important to analyze the extent to which its course has been influenced by several alternative payment instruments used in the intermediation of commercial transactions. Among the alternative payment instruments, this paper examines the impact of some of the components of interbank electronic clearing subsystem, namely interbank cheques clearing and interbank electronic funds transfer, on currency in circulation in Mozambique, using monthly data between 2010 and 2019. Preliminary analysis of the data revealed a decreasing trend in interbank cheques clearing against an increase in interbank electronic funds transfer, which is in line with the trends registered in some countries referenced in this paper. A Vector Error Correction Model was used based on the cointegration behavior of the variables used. The empirical results suggested that, interbank cheques clearing substitute currency while interbank electronic funds transfer complement it. Thus, this allows us to conclude that, generally, the beneficiaries of interbank electronic funds transfer convert funds ordered into cash, whereas the beneficiaries of cheques transacted via interbank clearing prefer to keep funds into deposits. However, the statistical significance of the latter was tenuous.
\end{abstract}

Keywords: Cointegration, Cheques Clearing, Currency in Circulation, Interbank Funds Transfer, Vector Error Correction Model

\section{Introduction}

The emergence of automated teller machine and electronic funds transfer at point of sale, different forms of digital currency, including cashless society is a clear indicator of a reduction of the dependence on cash for carrying out transactions. However, even though there are scenarios of change, cash remains the most widely used means of payment worldwide. In less advanced economies, inadequate financial education and literacy regarding the economic importance of using alternative means of payment, the cost associated with their use, and the slowness which the public adapts to the new means of payment are the main constraints for effective use of alternative means of payment to cash. These factors are coupled with weak banking system and the relatively high weight of informal market, which often operates outside the banking system. Thus, cash, although inconvenient to pay large amounts, especially when the distance between players is considerable, remains the most used means of payment in "day-to-day" transactions, as it is, among others, of practical use, confidential, and of immediate liquidity.

In addition to the alternative means of payment already mentioned, there are others payment methods that also play the same role. This paper analyzes the impact of some interbank electronic clearing subsystem instruments, namely interbank cheques clearing and interbank electronic funds transfer, on currency in circulation in Mozambique. It is not intended to exhaust this crucial matter about the preferences of consumers per different payment instruments in carrying out their transactions. Indeed, it is supposed to be the first of a series of papers to be produced, addressing the impact of different payment subsystems on currency in circulation in Mozambique. In this way, it is intended to contribute to the global reflection on the future of cash, given the emergence of various instruments and forms of payment, as well as 
institutions that seek to restrict the use of cash.

The paper is organized as follows. Section 2 presents theoretical background. Section 3 addresses the hypotheses and the methodology used. Section 4 provides a description of the data as well as the econometric model used. A summary of the results is presented in Section 5 and, finally, Section 6 presents the conclusions.

\section{Theoretical Background}

The relative advantages and costs of different payment instruments will largely determine whether and to what degree electronic payment instruments will displace cash. Some noncash payment instruments (such as credit and debit cards and interbank electronic clearing subsystems) involving intermediaries such as commercial banks and central banks address some of the shortcomings of cash payments. These subsystems can execute payments over physical distance, allow businesses and consumers to avoid some of the costs and risks of using cash, and are run by generally trusted and closely regulated intermediaries. However, the maintenance and operation of legacy noncash subsystems involve their own costs, and the intermediaries charge fees to recoup those costs and earn profits. The time it takes to finalize certain transactions, including crediting customer accounts for cheques or electronic funds transfers, can lead to consumers incurring additional costs. Additionally, these subsystems involve cybersecurity risks and generally require customers to divulge their private personal information to gain system access, which raises privacy concerns [5].

Among the range of instruments that can replace cash as an intermediary of exchange, we highlight here some that are components of the electronic clearing subsystem. As in other countries, Mozambique pays special attention to the operations of this payment subsystem, with adoption of specific regulations and mechanisms that guarantee efficiency in processing, clearing and settlement of funds and financial instruments [2]. Fluidity in electronic clearing and settlement of funds can help to curb the use of cash. However, it is recognized that, with the emergence of more attractive and practical means of payment, some traditional instruments, such as cheques, tend to lose their space [8]. Previous studies on this matter are scarce for developing economies and to best of our understanding none exists for Mozambique.

For this paper we focus on three payment instruments, namely [18]:

1) Cash payments: refers to payments made using banknotes and coins and are usually associated with face-to-face transactions of low value between individuals or between an individual and a merchant;

2) Interbank funds transfer subsystem: is a payment subsystem in which all (or almost all) participants are credit institutions. Consequently, this is an arrangement through which funds transfer are made between banks for their own account and on behalf of their customers;

3) Cheque: is a written order from one party (the drawer) to another (the drawee) requiring the drawee to pay a specified sum on demand to the drawer or a third party specified by the drawer.

In order to achieve the desired objective, the dynamics of currency in circulation, as well as alternative payment instruments of interest, are addressed below. We start with currency in circulation, which refers to the amount of cash held by the public, largely for carrying out transactions. The figure 1 shows a monthly evolution of the series of currency in circulation in Mozambique, from 2010 to 2019. The figure shows that this series exhibits frequent oscillatory movements and an increasing trend, which suggests a seasonal pattern. In fact, from January to March, as well as August to October, the demand for cash is relatively low, these are months associated with a return of cash to the financial system (banks) via deposits. However, April to July the demand for cash is high because, amid several factors, of the agriculture trade campaigns. Likewise, November and December are months of high demand for cash to cover typical expenses of festive season.

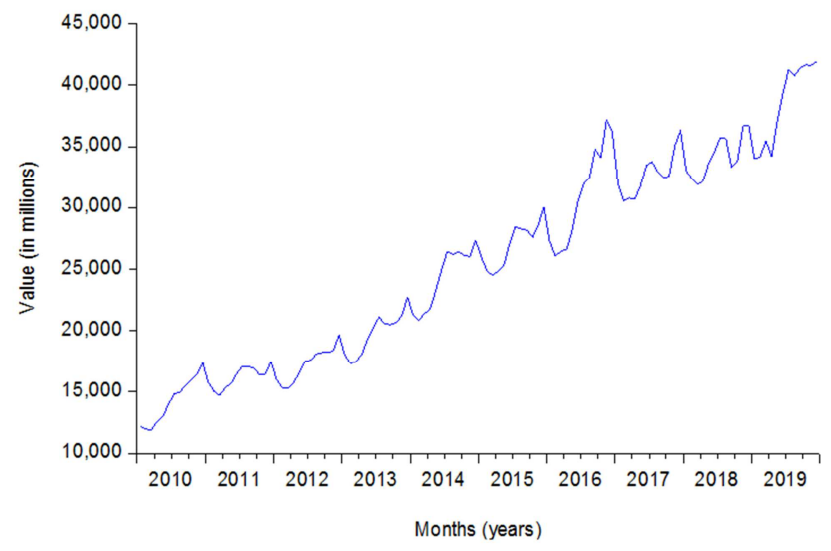

Figure 1. Currency in circulation in Mozambique.

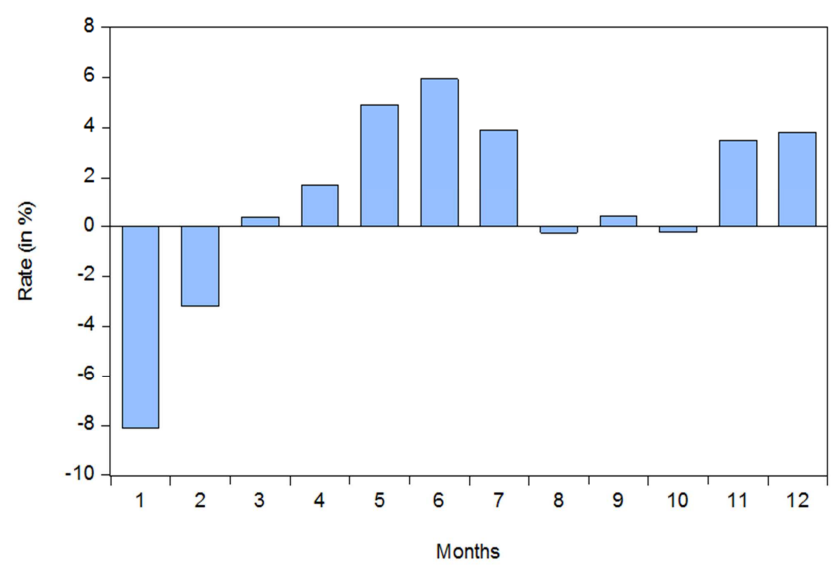

Figure 2. Monthly average change in currency in circulation.

Figure 2 supports the above finding. According to this figure, from 2010 to 2019 , the monthly average variation rate in the currency in circulation in Mozambique was negative in January and February, which reflects the return of cash released to the economy in the last months of the previous year. 
As of April, generally, with the State's budget already approved, the dynamic of the economy activity begins, with emphasis on agriculture trade campaigns, whose peak occurs in June. Given a weak penetration of banking system network, when agricultural marketing takes place, the return of cash to the banks is slow, since agriculture trade campaign takes place in rural areas without bank branches. However, the return of this cash starts in August, which contributes to the deceleration of currency in circulation.

Despite the growing trend evidenced by the series of currency in circulation, in the same period, the coefficient of public's preference for cash, an indicator used to measure the level of public preference for using banknotes and coins in economic transactions, obtained from the currency in circulation ratio to total deposits in the economy (both denominated in Metical - the national currency), revels a decreasing trend, from $20.20 \%$ in January 2010 to $13.37 \%$ in December 2019 , with a maximum of $24.97 \%$ in November 2010 and minimum of $11.91 \%$ in February 2016 (see figure 3).

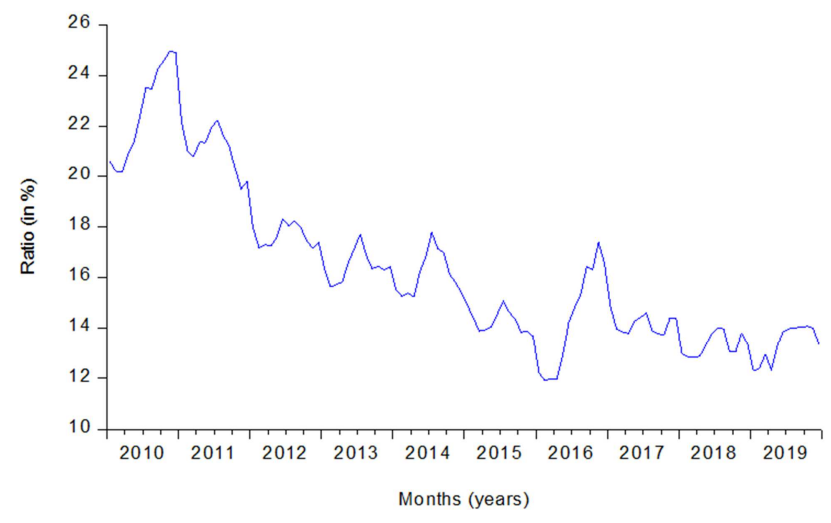

Figure 3. Public preference for cash.

The downward trend revealed by public's preference for cash graph suggests the public's option to use other means of payment in their transactions other than cash. Indeed, globally, over the past three decades the most significant long-term trend in the use of payment instruments has been the relative shift away from cash in favor of noncash payment methods for consumer payments, combined with increases in electronic and automated processing of payments more generally. The use of internet banking and online shopping has also increased considerably, allowing buyers to make payments regardless of location or time [18]. Mozambique, could not be unaware of this global trend.

In the case of the instruments transacted in interbank electronic clearing, namely interbank cheques clearing and interbank electronic funds transfer, analysis of the data reported by the Bank of Mozambique indicate that, on average, from January 2010 to December 2019, commercial banks cleared 165,378 cheques themselves, while electronic funds transfer stood at 99,955 operations [21].

Nevertheless, figure 4 shows the volume of cleared cheques in the period under review on an annual basis. According to the figure, the graph presented shows a decreasing trend. In fact, data analysis made allowed us to conclude that there was a reduction in the volume of cheques cleared. Indeed, $2,013,827$ cheques were cleared in 2010 , having dropped to $1,718,258$ cheques in 2019 , which corresponds to a reduction of $14.68 \%$ (295,569 cheques).

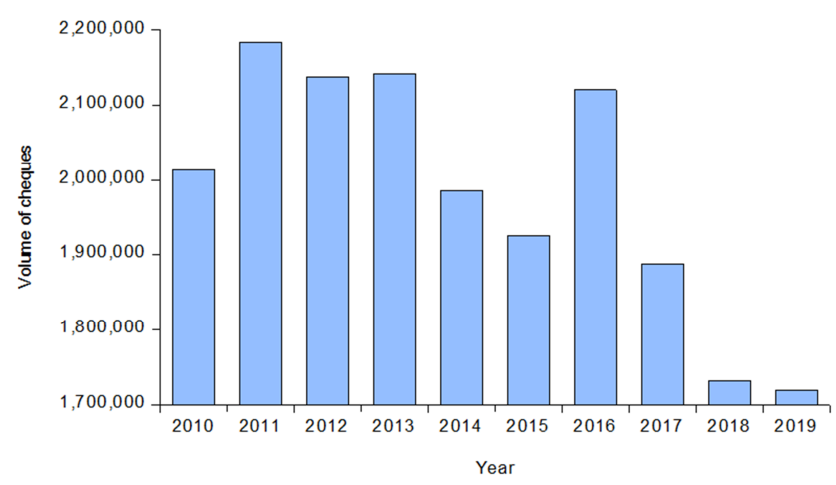

Figure 4. Volume of cleared cheques.

Contrary to the cheques, whose graph suggests a downward trend, the graph of interbank electronic funds transfer shows an increasing trend, according to the figure 5.

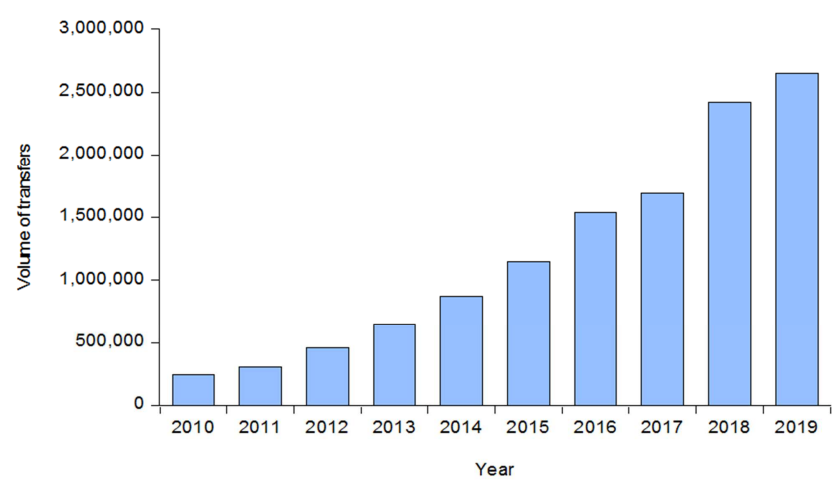

Figure 5. Volume of interbank electronic funds transfer.

Confirming the trend of the graph, data analysis indicated that interbank electronic funds transfer went from 246,734 in 2010 to $2,650,008$ in 2019 , which corresponds to a positive variation of $974.03 \%(2,403,274$ transfers $)$. This evolution suggests a relatively greater importance of interbank electronic funds transfer than interbank cheques clearing, in the set of electronic clearing instruments considered in this paper. It should be noted that, as a paper-based instrument, cheques are the costliest noncash payment instrument to process and settle. As a result, payment service providers are seeking ways of reducing costs through the dematerialization of the clearing and settlement process (via the truncation of cheques, where only an electronic image of the cheque is processed) [18].

The evolution of electronic clearing instruments in Mozambique denotes a similarity with the trends observed at least in some compared countries. In Zambia, 2,632,969 cheques were cleared in 2010 to $1,794,631$ cheques cleared in 2019 , which corresponds to a reduction of $31.84 \%(838,338$ cheques). Regarding interbank electronic funds transfer, in the 
same period they registered an increase of $257.41 \%$ $(5,618,178$ transfers), from $2,182,542$ transfers in 2010 to $7,800,720$ transfers in 2019 [13].

In Angola there was a similar trend, cheques clearing decreased from 461,700 cheques in 2010 to 130,554 cheques in 2019 , a negative variation of $71.72 \%$ (331,146 cheques). Interbank electronic funds transfer went from 120,114 in 2012 to $11,468,311$ transfers in 2019 , which corresponds to a huge increase of $9,447.86 \%(11,348,197$ transfers $)$ [12]. Same scenario occurred in Cape Verde, which recorded a $15.63 \%$ reduction in cheques cleared, from 357,920 in 2010 to 301,960 cheques in 2019. In the same period, interbank electronic funds transfer registered an increase of $1,180.27 \%(682,161$ transfers) from 57,797 to 739,958 transfers [11].

Note that, during the period under review (2010 to 2019), the referenced countries registered an increase in currency in circulation. Mozambique recorded the highest increase of $141.14 \%$ and Cape Verde the lowest increase of $17.22 \%$.

However, specific observation regarding the use of cheques, points out that, while some European Union countries have implemented policies to discourage its use [19], the decreasing trend in the use of cheques cannot be generalized, mainly in less advanced economies. On average, the number of cheques written in the top 10 countries, that use them the most, dropped by $6.00 \%$ per year, between 2007 and 2017, while in certain places, this trend is reversed, and cheques usage has held steady, or even increased, over the same period. This trend occurs, especially in places where unbanked consumers are joining the formal financial system in huge numbers, either because of rapid economic growth or ambitious policy and infrastructure projects that have made access easier. Many of these countries are in the Asia-Pacific region or the Indian subcontinent. Several of them, including the Philippines, appear poised to continue their reversal of cheque decline well into the next decade [6].

\section{Hypotheses and Methodology}

This paper analyzes the impact of some electronic clearing subsystem instruments, namely interbank cheques clearing and interbank electronic funds transfer on currency in circulation in Mozambique. Thus, the hypotheses to be tested are as follows:

i. increase of interbank cheques clearing and interbank electronic funds transfer lead to a reduction of currency in circulation, if final beneficiaries do not choose to convert deposited and transferred funds into cash;

ii. increase of interbank cheques clearing and interbank electronic funds transfer lead to an increase in currency in circulation if the final beneficiaries choose to convert deposited and transferred funds into cash.

The main methodology used is as follow:

a) characterization of the data, performing a graphical analysis and descriptive statistics of the series under study;

b) analysis of stationarity, using unit root tests;

c) if the variables are stationary, a Vector Autoregressive
(VAR) model will be estimated;

d) if the variables are not stationary, a cointegration test will be performed;

e) if there is a cointegration relationship among variables, a Vector Error Correction (VEC) model will be estimated;

f) carrying out a diagnostic tests and structural analysis of the estimated model;

g) analysis and interpretation of the results; and

h) point out the findings of the study.

\section{Data and Econometric Model}

\subsection{Preliminary Analysis of the Variables}

To model the impact of electronic clearing on currency in circulation in Mozambique a monthly sample covering a period of ten years (2010 to 2019), which corresponds to 120 observations, was used. The variables used are as follows:

1) Currency in circulation $\left(\mathrm{CiC}_{t}\right)$ : considered in value and in a strict sense. It is the amount of cash that, effectively, the public holds, due on the need to conduct transactions. Thus, this excludes notes and coins in the vault of the deposit-taking institutions;

2) Cheques $\left(\mathrm{CHQ}_{t}\right)$ : represent the volume of cheques drawn, cleared and settled. This does not include other cheques that are settled using the bank tellers;

3) Interbank electronic funds transfer $\left(I_{F} T_{t}\right)$ : represent the volume of transfers ordered electronically using the various infrastructures available for this purpose;

4) Credit to economy $\left(C R E_{t}\right)$ : represent the total value of the credit made available to the economy. Used as a proxy for the performance of economic activity.

Table 1 shows the descriptive statistics of the variables used, for the sample period considered.

Table 1. Descriptive Statistics.

\begin{tabular}{lllll}
\hline Description & CiC & IFT & CHQ & CRE \\
\hline $\mathrm{N}^{\text {o }}$ of observ. & 120 & 120 & 120 & 120 \\
Mean & 25,511 & 99,955 & 165,378 & 167,135 \\
Median & 26,050 & 77,858 & 165,729 & 185,298 \\
Maximum & 41,943 & 280,638 & 256,963 & 274,859 \\
Minimum & 11,930 & 14,673 & 78,857 & 65,233 \\
Std. Dev. & 8,363 & 71,590 & 24,412 & 64,749 \\
Skewness & 0.16 & 0.70 & 0.61 & -0.07 \\
Kurtosis & 1.82 & 2.34 & 5.95 & 1.44 \\
Jarque-Bera & 7.51 & 11.97 & 51.17 & 12.27 \\
Probability & 0.02 & 0.00 & 0.00 & 0.00 \\
\hline
\end{tabular}

According to table 1, all variables are asymmetric, while CRE has a negative asymmetry, the rest of the variables has positive asymmetry. In relation to normality, in line with the fact that the variables are asymmetrical, the kurtosis coefficients show that they have a "platikurtic" distribution, since the respective kurtosis coefficients are less than three (with exception of CHQ with "leptokurtic" distribution) [15]. Finally, considering a level of significance of 5\%, Jarque Bera statistics confirms that all variables were not generated from a 
normal distribution.

To perform the intended analyzes, the data have been transformed to logarithms, being thus identified by lowercase
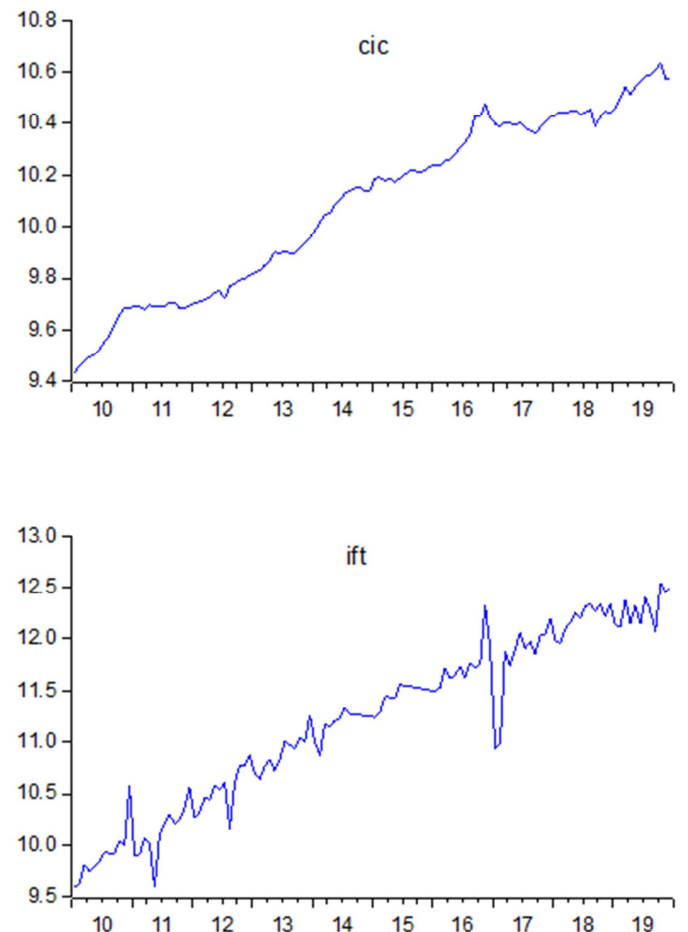

letters (cic, ift, chq and cre), whose monthly graphs are shown in figure 6.
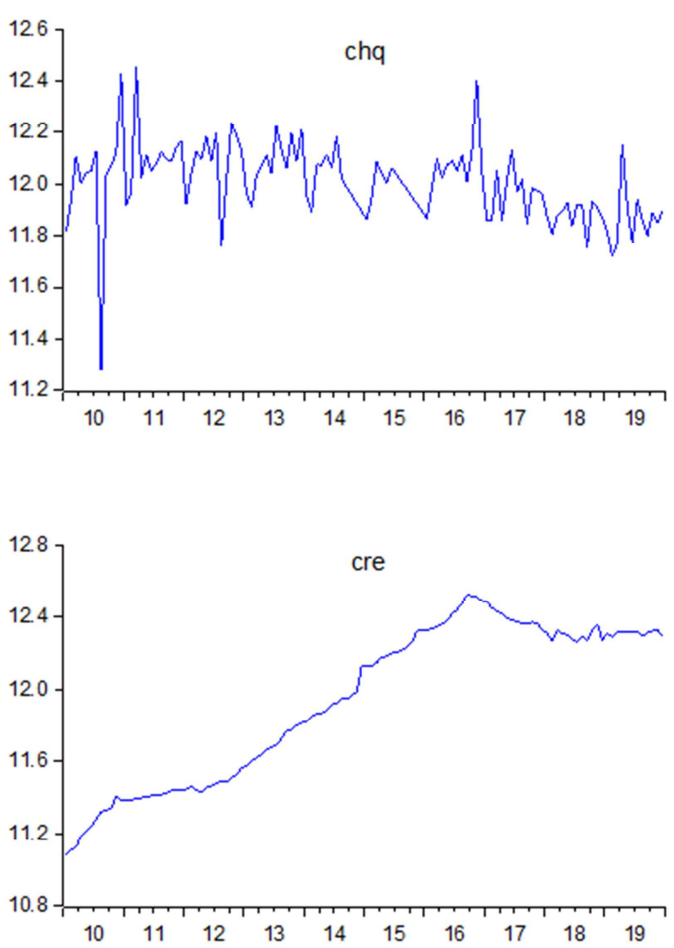

Figure 6. Series graphs in logarithms.

According to figure 6, except the $c h q$ graph which shows a slight downward trend, the remaining graphs clearly show an upward trend.

\subsection{Stationarity Analysis - Unit root tests}

The identification of the order of integration of a time series is essential in any empirical study involving time series, since, among other aspects, the importance of the stationarity analysis is related to the fact that the choice of the model depends on the behavior of time series involved. The verification of the presence of unit roots was carried out using Augmented Dickey-Fuller (ADF) tests for each of the variables. The test equation is as follows [9]:

$$
\Delta Y_{t}=\alpha_{0}+\alpha_{1} t+\phi Y_{t-1}+\sum_{i=1}^{p-1} \gamma_{i} \Delta Y_{t-1}+\varepsilon_{t}
$$

In equation (1), $\Delta$ represents the differentiation sign, $\alpha_{0}$ and $\alpha_{1} t$ are deterministic components (intercept and linear trend, in cases where the variable has no trend, $\alpha_{1} \cong 0$ ). The parameter of interest is $\phi$. Thus, if $\phi$ is statistically equal to zero $(\phi=0)$, it is inferred that the variable $Y_{t}$ has a unit root. $\sum_{i=1}^{p-1} \gamma_{i} \Delta Y_{t-1}$ is an expression that represents the length lags required to guarantee enough dynamic in the model to avoid autocorrelation in errors. Finally, $\varepsilon_{\mathrm{t}}$ is the error component. Formally, the hypothesis to be tested are the following,

$$
\mathrm{H}_{0}: \phi=0 \text { versus } \mathrm{H}_{1}: \phi<0,
$$

and the test statistic is,

$$
\tau_{c t}=\frac{\hat{\phi}}{\operatorname{se} \hat{\phi}} \stackrel{\mathrm{d}}{\rightarrow} \text { DF under } \mathrm{H}_{0}
$$

this is the Dickey-Fuller (DF) statistic; whose distribution is not standard.

The unit root tests performed provided the following results:

Table 2. Unit root and stationary testes.

\begin{tabular}{lll}
\hline & $\boldsymbol{\tau}_{A D F}-$ level & $\boldsymbol{\tau}_{A D F}-$ first diference \\
\hline Cic & $-1.95(0,621)$ & $-10.40(0,000)$ \\
Ift & $-1.53(0,813)$ & $-5.76(0,000)$ \\
Chq & $-2.71(0,074)$ & $-6.40(0,000)$ \\
Cre & $-0.09(0,997)$ & $-10.77(0,000)$ \\
\hline
\end{tabular}

Note: P-value in ().

Accordingly, statistical evidences suggested that, each of the variables presented in table 2 has a unit root. Thus, the variables are not stationary.

\subsection{Cointegration Tests}

The time series making up " $Y_{t}$ " are cointegrated if the linear combination $\beta^{\prime} Y_{t}$ are $\mathrm{I}(0)$ random variables. If $Y_{t}$ are not cointegrated, then $\beta^{\prime} Y_{t}$ would be $\mathrm{I}(1)$ for any non-zero vector $\beta$. Tests of cointegration ask whether $\beta^{\prime} Y_{t}$ is $\mathrm{I}(0)$ or $\mathrm{I}(1)$ [16].

The unit root tests carried out in section 4.2 allowed us to conclude that, the variables under study are integrated. Thus, it 
is necessary to perform a cointegration test, which will provide subsidies to choose the model to be estimated, between VEC model, if the linear combination of the time series is I (0), and VAR model, after differentiating the series to make them stationary, if the linear combination of the series is $\mathrm{I}(1)$.

Johansen's procedure which comprises two modalities namely, trace test and maximum-eigenvalue test were used to verify the presence or not of cointegration relationship between the variables under study [7]. The respective tests statistics are as follows:

$$
\begin{aligned}
& J_{\text {trace }}=-T \sum_{i=r+1}^{n} \ln \left(1-\hat{\lambda}_{i}\right) \\
& J_{\text {max }}=-T \ln \left(1-\hat{\lambda}_{r+1}\right)
\end{aligned}
$$

where $\mathrm{T}$ represents the sample size, $\hat{\lambda}_{i}$ is the largest canonical correlation.

The trace test tests the null hypothesis of $r$ cointegrating vectors against the alternative hypothesis of $n$ cointegrating vectors, on the other hand, the maximum eigenvalue test tests null hypothesis of $r$ cointegrating vectors against the alternative hypothesis of $r+1$ cointegrating vectors. These statistics have no standard asymptotic distribution, they depend of degrees of freedom, the inclusion or not of drift and/or trend, and their distributions are tabulated by simulation [16]. As a scale variable, cre will not be included in cointegration relationship.

The tests carried out provided the following results: trace test, $\left(\mathrm{H}_{0}: r=0\right)$ versus $\left(\mathrm{H}_{1}: r=1,2,3\right)$, rejected the null hypothesis of absence of cointegration relationship at $5 \%$ significance level, since $J_{\text {trace }}=42.86\left(p_{\text {value }}=0.00<\right.$ 0.05). To check for the existence of more than one cointegration relationship, one more trace test was performed, whose $J_{\text {trace }}=17.66 \quad\left(p_{\text {value }}=0.02<0.05\right)$, which rejected the null hypothesis of the absence of one more cointegration relationship. However, the test was not favorable for the existence of a third cointegration relationship.

Like the previous test, the maximum-eigenvalue test, also supported the existence of two cointegration relationship. The test $\left(\mathrm{H}_{0}: r=0\right)$ versus $\left(\mathrm{H}_{1}: r=1\right)$, with $J_{\max }=25.20$ $\left(p_{\text {value }}=0.01<0.05\right)$ rejected the null hypothesis of absence of cointegration relationship at $5 \%$ significance level. Additionally, the test $\left(\mathrm{H}_{0}: r=1\right)$ versus $\left(\mathrm{H}_{1}: r=2\right)$ whose $J_{\max }=17.27$ ( $\left.p_{\text {value }}=0.02<0.05\right)$ was not favorable to the null hypothesis.

\subsection{Vector Error Correction Model}

The tests carried out in the previous sections allowed us to conclude that the variables under study are integrated and are cointegrated, they establish a long-term relationship. Thus, it is more plausible to estimate a VEC model for the following reasons [10]:

1) It allows to know the interactions between the variables;

2) It allows to know the long-term equilibrium relationships between the variables;

3) It allows to identify the causal relationships;
4) It allows to know the dynamics of the variables.

Let consider $Y_{t}$ a vector of endogenous variables (cic, chq and ift) and $W_{t}$ a vector of exogenous variables (cre), the VEC (P) model, where "P" represents the lag length, has the following representation:

$$
\Delta Y_{t}=A_{0}+\Pi Y_{t-1}+\sum_{i=1}^{p-1} \Gamma_{i} \Delta Y_{t-1}+A_{j} W_{j}+\varepsilon_{t}
$$

here $A_{0}$ is the vector of independent terms, $\Pi$ is the number of cointegrating vectors and $A_{j}$ is the coefficient matrix of exogenous explanatory variables.

\subsubsection{Model Estimation}

We used Eviews statistical package to estimate the VEC given in equation (4). Five criteria were used to choose lag length "P". Accordingly, Schwarz information (SC) and Hannan-Quinn information (HQ) criteria propose $\mathrm{P}=2$, while Akaike information (AIC), Final Prediction Error (FPE) and Sequential modified LR test statistic (LR) criteria propose $\mathrm{P}=$ 5. So, $\mathrm{P}=5$ was chosen, consequently, VEC (5) was estimated.

The following output shows the estimated model. In order

\begin{tabular}{|c|c|c|c|}
\hline Cointegrating Eq: & & CointEq1 & \\
\hline $\operatorname{cic}(-1)$ & & 1.000000 & \\
\hline $\operatorname{chq}(-1)$ & & 0.176464 & \\
\hline \multirow{5}{*}{ ift(-1) } & & $(0.14424)$ & \\
\hline & & [1.22337] & \\
\hline & & -0.251403 & \\
\hline & & $(0.03847)$ & \\
\hline & & {$[-6.53544]$} & \\
\hline $\mathrm{C}$ & & -9.400298 & \\
\hline Error Correction: & D(cic) & $\mathrm{D}(\operatorname{chq})$ & D(ift) \\
\hline \multirow[t]{3}{*}{ CointEq1 } & -0.164 & 0.068 & 0.579 \\
\hline & $(0.041)$ & $(0.311)$ & $(0.391)$ \\
\hline & {$[-3.981]$} & {$[0.218]$} & [1.480] \\
\hline
\end{tabular}
to allow better analysis, short-term estimates were suppressed.

Table 3. Vector Error Correction Estimates.

Note: Standard errors in ( ) and t-statistics in [ ].

\subsubsection{Adjustment for Long-term Equilibrium}

The estimated VEC (5) suggests the following:

1) About $16 \%$ of the disequilibrium in currency in circulation are corrected each month due to the change in cic;

2) About $7 \%$ of the disequilibrium in currency in circulation are corrected each month due to the change in chq;

3) About $58 \%$ of the disequilibrium in currency in circulation are corrected each month due to the change in ift;

However, the adjustment estimates for long-term equilibrium of $c h q$ and ift are not statistically significant at a level of $5 \%$, which suggests the weakness of the error correction mechanism in this model.

\subsubsection{Long-term Relationships}

From the estimated VEC (5), the long-term relationship was 
extracted (cointegrating equation).

$$
\beta \text { cic }=\operatorname{cic}+0.176 \mathrm{chq}-0.251 \text { ift } \mathrm{I}(0)
$$

To analyze all long-term relationship, the following normalizations were performed:

$$
\begin{gathered}
\text { cic }=0.251 \mathrm{ift}-0.176 \mathrm{chq} \\
\mathrm{chq}=1.426 \mathrm{ift}-5.682 \mathrm{cic} \\
\text { ift }=4.000 \mathrm{cic}+0.701 \mathrm{chq}
\end{gathered}
$$

Equation (6) shows that an increase in ift by $1 \%$ causes an increase in cic by about $0.251 \%$, an increase in $c h q$ by $1 \%$ leads to a reduction in cic by about $0.176 \%$. Furthermore, from equation (7) it is noted that, an increase in ift by $1 \%$ leads to an increase in $c h q$ by about $1.426 \%$ and an increase in cic by $1 \%$ leads to a reduction in $c h q$ by about $5.682 \%$. Finally, equation (8) suggests that an increase in cic by $1 \%$ leads to an increase in ift by about $4.000 \%$, while an increase in chq by $1 \%$ is associated with an increase in ift by about $0.701 \%$.

\subsubsection{Stationarity}

According to figure 7, the estimated VEC model appears to be stationary in covariance, as the inverses of the root modules of its characteristic equation of the autoregressive component are within the unitary circle.

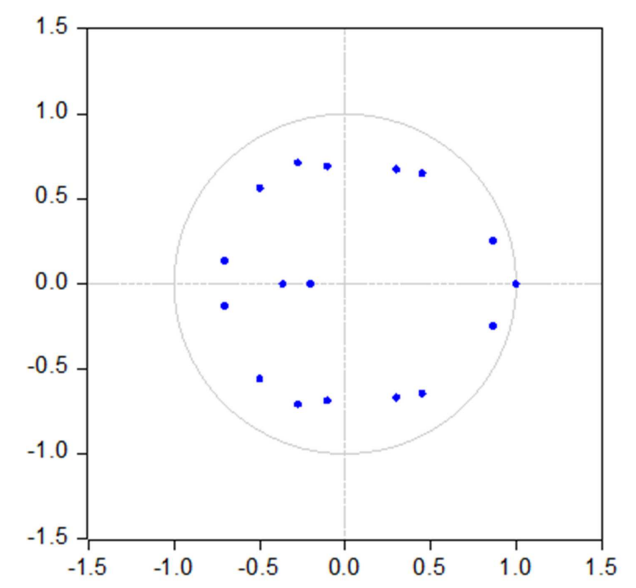

Figure 7. Inverse roots of AR characteristic polynomial.

\subsubsection{Diagnostic Tests}

Autocorrelation: Portmanteau autocorrelation test supported the null hypothesis of absence of residual autocorrelations at a significance level of $5 \%$. Thus, statistically it allowed us to conclude that, the residues exhibit a similar white noise behavior.

Multivariate normality: regardless of the method used for orthogonalization of the residues (Choleski, Doornik-Hansen and Urzua), the multivariate normality test rejected the null hypothesis that the residues present a multivariate Gaussian distribution.

Heteroscedasticity: White's heteroscedasticity test, without cross products, did not reject the null hypothesis of unconditional homoscedastic errors in the estimated model equations, at a $5 \%$ significance level. However, due to the sample size, it was not possible to perform the test with cross products.

\subsubsection{Structural Analysis of the Model}

Granger causality: a variable X Granger causes $\mathrm{Y}$ if the inclusion of $\mathrm{X}$ to predict $\mathrm{Y}$, effectively improves $\mathrm{Y}$ 's prediction. Indeed, if in an informative universe the removal of the history of a variable does not change the joint distribution of any of the remaining variables, then the omitted variable is referred to in terms of Granger's causality as not causing the remaining variables. A formal approach to Granger causality can be found in [14].

As the concept has been generally presented, now, we focus on the results of Granger causality tests. First, pairwise Granger causality tests results are presented. All tests were carried out considering 5\% significance level. Considering one period length lag, the tests were favorable to the existence of bidirectional causality between $c h q$ and ift, unidirectional causality from $\mathrm{cic}$ to $\mathrm{ch} q$ and from $\mathrm{cic}$ to ift. Taking into account six length lags, the tests were favorable for the existence of bidirectional causality between ift and cic and unidirectional causality from $c h q$ to ift. Regarding twelve length lags, the tests supported the existence of unidirectional causality from cic to $c h q$ and from $c h q$ to ift. Finally, considering 24 length lags, the tests were not favorable to any causality relationship. Therefore, as time goes on, the process loses its memory.

The second test conducted in the scope of Granger causality was the wald test for Granger causality. Unlike the previous test, this one was arried out taking into account the estimated model and has the particularity of testing the exogeneity of the variables. Accordingly, the test was only favorable to the existence of causality from ift for cic. However, doing combined causality analysis, the test supported a joint causality of ift and $c h q$ for cic, and of cic and chq for ift. The test did not suggest any causality for $c h q$.

Impulse response functions: these functions define the effect of an exogenous shock of a random disturbance on the present and past values of an endogenous variables. Granger causality may not give all information about the interactions of variables in the system. Thus, in an applied research it is always of interest to know the response of one variable to an impulse in another variable. If there is a reaction, the latter causes the former [10].

Using the generalized impulse response function, the results suggested that, shock in cic leads to fall of cic itself. Shocks in chq and ift cause a drop in cic in the first three periods, followed by periods of growth. As for $c h q$ response, it appears that, it responds positively to shock in cic until third period, followed by periods of oscillation, but in general with a decreasing trend. In relation to its own shock, $c h q$ registers an abrupt decrease until third period, then it grows in the fourth, sixth and seventh periods, and decrease in the remaining periods. $c h q$ response to the impulse on ift is tenuous, with a decrease in third and sixth periods.

Regarding to ift, it responds positively to shock in cic until 
third period, followed by a drop until sixth period, from where it resumes growth. ift's response to its own and $c h q$ 's shocks is similar, with an abrupt decrease until third period, followed by slight oscillatory movements.

Variance decomposition: variance decomposition of a forecast error appears as another tool to analyze the structural relationships between variables in the model. If it is possible to identify the innovations occurred in the system, it is also possible to decompose the variance of the forecast error, which allows measuring the relative importance of each random disturbance to other variables. Therefore, if the error of a given variable $X$ does not explain the variance of the error of a sequence $\{\mathrm{Y}\}$, then $\mathrm{Y}$ is exogenous. It meaning that $\mathrm{Y}$ changes independently of shocks from $\mathrm{X}$ and $\{\mathrm{X}\}[10]$.

Thus, analyzes made allowed to retain that, for $c i c$ and $c h q$, one-step forecast error variance is due to the innovations of the respective variables. For ift, one-step forecast error variance is due to about $68 \%$ of its own innovations, about $27 \%$ of $c h q$ innovations and about $5 \%$ of $\mathrm{cic}$ innovations. As the forecast length lag increases, there is a relative increase in the impact of shocks from other variables.

Considering twelve-month step forecasting error, it appears that $c i c$ is explained by about $81 \%$ of its own shocks, with $c h q$ and ift shocks falling at about $4 \%$ and $15 \%$, respectively. While $c h q$ is explained by about $93 \%$ of its own innovations, about $5 \%$ of the disturbances in $\mathrm{cic}$ and about $2 \%$ of the disturbances in ift. Finally, for ift, about $59 \%$ of its forecast error variance is explained by its own innovations, chq contributes significantly to explain forecast error variance in ift with about $29 \%$, while the contribution of cic is around $12 \%$. However, changing the order of variables in the VEC (5) model, there is also a change in the results of the variance decomposition of the forecast error.

\section{Results}

Below is a summary of the analyzes carried out previously.

1) Cointegration: statistical evidence allowed us to conclude that the variables are integrated. The cointegration tests, namely trace and maximum-eigenvalue tests, did not reject the hypothesis of existence of long-term relationships between the variables;

2) Model estimation: VEC (5) model was estimated. The long-term adjustment coefficients revealed that, in each month, about $16 \%$ of the disequilibrium in currency in circulation are corrected due to the change in currency in circulation itself, about $7 \%$ of the disequilibrium in currency in circulation are corrected due to the change in cheques, while about $58 \%$ of the disequilibrium in currency in circulation are corrected resulting to the change in interbank electronic funds transfer. The adjustment coefficients for the long-term equilibrium of cheques and interbank electronic funds transfer were not statistically significant at a level of $5 \%$, which suggests the weakness of the error correction mechanism in the estimated model. In the other hand, estimates of long-term relationships suggested that, at the end of the payment, beneficiaries of funds transferred via interbank electronic funds transfer tend to convert received funds into cash through withdrawals, which contributes to increase currency in circulation. Conversely, cheques beneficiaries, generally, do not turn to banks to convert received funds into cash, keeping them in deposit. However, statistical evidence indicates that its impact on currency in circulation is tenuous;

3) Diagnosis of the model: in general, the autocorrelation test of the residues did not reject the null hypothesis of the absence of autocorrelation in the residues. Regarding the joint normality test, it was not favorable to the normality of the residues. However, for the heteroscedasticity test, it did not reject the hypothesis of homoscedastic residues;

4) Structure of the model: Granger causality test (wald test for Granjer causality) only did not reject interbank electronic funds transfer causality for currency in circulation. However, considering the combined effect, the test was favorable of a joint causality of cheques and interbank electronic funds transfer for currency in circulation, and of cheques and currency in circulation for interbank electronic funds transfer. There was no evidence of causality for cheques, which suggests the exogeneity of this variable. Taking into account impulse response function, analyzes carried out corroborated the findings mentioned above. Currency in circulation responds to its own impulse and interbank electronic funds transfer impulse more sharply compared to the response to the impulse in cheques. The response of cheques to the impulse in currency in circulation and interbank electronic funds transfer is tenuous, contrary to what happens to its own impulse. Finally, interbank electronic funds transfer react considerably to its own impulse and impulses in other variables. Concerning to the variance decomposition of the forecast error, in all variables, the variance of one-step forecast error is due to the innovations of the respective variables. As the forecast length lag increases, there is a relative increase in impact of shocks from other variables. However, tests carried out with different ordering of the variables in the model, confirmed the instability of the impact of the variance decomposition, resulting of the use of Choleski matrix for decomposition of the error covariance matrix.

\section{Conclusions}

In this paper, we analyzed the impact of some interbank electronic clearing subsystem instruments, namely interbank cheques clearing and interbank electronic funds transfer on currency in circulation in Mozambique.

Two hypotheses were posed, assuming that electronic interbank clearing could influence trend of currency in circulation in Mozambique, considering a scenario in which the final beneficiaries of funds may or may not choose to convert their funds into cash. Statistical evidences supported 
both hypothesis. The results suggested that, the beneficiaries of interbank electronic funds transfer, generally convert received funds into cash, contributing to increase of currency in circulation. However, the beneficiaries of cheques transacted via interbank clearing, generally do not convert their funds into cash, whereby whose impact on currency in circulation is negative. However, this impact proved to be statistically insignificant.

\section{References}

[1] A. Silvestre. (2007). Análise de Dados e Estatística Descritiva. Escolar Editora. Lisboa.

[2] Assembleia da República. (2008). Lei $\mathrm{n}^{\mathrm{o}} 2 / 2008$, of $27^{\text {th }}$ February. Maputo.

[3] B. Muriftra, C. Ribeiro, and J. Silva, and C. Pimenta. (2010). Introdução à Estatística. Escolar Editora. Lisboa.

[4] D. Hendry. (1995). Dynamic Econometrics. Oxford University Press.

[5] D. Perkins. (2019). Long Live Cash. The Potential Decline of Cash Usage and Related Implications. Congress Research Service. Washington.

[6] Digital Check Corp. (2019). The Reappering Cheque: Why Cheuqe Usage is on the Rise in Some Developing Countries. USA.

[7] E. Hjalmarsson and P. Österholm. (2007). Testing for cointegration using the Johansen methodology when variables are near-integrated. IMF Working Paper 07/141. (Washington: International Monetary Fund).
[8] E. Tellez. (2017). The Ongoing Decline of the Cheque System. Reserve Bank of Australia. Quarter Bulletin/June, pp. 57-65.

[9] F. Hayashi. (2000). Econometrics. Princeton University Press.

[10] H. Lütkepohl. (2005). New Introduction to Multiple Time Series Analysis. Springer. New York.

[11] https://www.bcv.cv/ (consulted on 10/07/2020).

[12] https://www.bna.ao/ (consulted on 10/07/2020).

[13] https://www.boz.zm/ (consulted on 10/07/2020).

[14] J. Hamilton. (1994). Time Series Analysis. Princeton University Press.

[15] J. Nicolau. (2012). Modelação de Séries Temporais Financeiras. Edições Almedina. Coimbra.

[16] R. Davidson and J. MacKinnon. (1993). Estimation and Inference in Econometrics. Oxford: Oxford University Press.

[17] S. Durlauf and L. Blume. (2010). Macroeconometrics and Time Series. Rhe New Palgrave Economic Collections. Palgrave Macmillan. United Kingdom.

[18] T. Kokola. (2010). Payments, Securities and Derivatives, and the Role of the Eurosystem. European Central Bank.

[19] V. Silva, E. Ramalho and C. Vieira. (2016). The Use of Cheques in the European Union: a Cross-Country Analysis. University of Evora. Portugal.

[20] W. Wei. (2006). Time Series Analysis: Univariate and Multivariate Methods. 2nd Ed, Addison-Wesley.

[21] www.bancomoc.mz (consulted on 10/07/2020). 